\title{
PENGEMBANGAN PRODUK KRIPIK TELA ANEKA RASA DAN STRATEGI PEMASARANNYA UNTUK KESEJAHTERAAN KELOMPOK WANITA RENGGANIS JEMBER
}

\section{THE DEVELOPMENT OF VARIOUS TASTE OF TELA CHIP PRODUCTS AND ITS MARKETING STRATEGY FOR WOMEN'S RENGGANIS JEMBER GROUP}

\author{
Aulia Brilliantina ${ }^{\# 1}$, Elok Kurnia Novita Sari" ${ }^{\# 2}$, Irene Ratri Andia Sasmita ${ }^{\# 3}$ \\ \#Jurusan Teknologi Pertanian, Politeknik Negeri Jember \\ Jalan Mastrip Kotak Pos 164 Jember \\ 1aulia_b@polije.ac.id \\ ²elok_kurnia@polije.ac.id \\ 3ireneratriandiasasmita@polije.ac.id
}

\begin{abstract}
Abstrak
Ubi jalar merupakan salah satu bahan pangan yang mengandung karbohidrat yang memiliki keunggulan dibandingkan dengan sumber karbohidrat lainnya. Salah satu kecamatan di Kabupaten Jember yang paling banyak membudidayakan tanaman ubi jalar adalah Kecamatan Panti, Desa Pakis, Dusun Kemundungan. Kelompok tani selama ini menjual ubi dalam bentuk umbi segar dengan harga sangat murah, mulai dari harga Rp 500, - hingga Rp 1.500, - per kilonya. Dalam rangka mendukung pembangunan pertanian menuju terwujudnya pertanian unggul yang berkelanjutan berbasis sumber daya lokal, tim pengabdian kami akan melaksanakan program "Pengembangan Produk Keripik Ubi Jalar Beragam Rasa dan Strategi Pemasarannya untuk Kesejahteraan Kelompok Wanita Tani Rengganis di Jember" untuk meningkatkan kemandirian pangan, nilai tambah, daya saing dan kesejahteraan petani.Metode: Jenis pelatihan yang akan diberikan meliputi pelatihan pembuatan keripik dengan metode Deep Frying, serta memberikan pelatihan strategi pemasaran agar produk dapat berkembang dan laku di pasaran. Pelaksana kegiatan terdiri dari satu orang ketua pelaksana yang berkompeten di bidang kewirausahaan, dan satu orang pelaksana yang berkompeten di bidang mekanisasi alat pengolah makanan. Hasil: Luaran yang ingin dicapai adalah peningkatan daya saing dan penerapan iptek bagi komunitas perempuan petani di Rengganis, Jember. Kegiatan ini akan dilaksanakan selama 8 bulan dengan total biaya yang dibutuhkan sekitar Rp. 47.500.000. Kesimpulan: Meningkatnya pengetahuan dan daya saing perempuan petani di Rengganis, Jember.
\end{abstract}

Kata kunci: Ubi jalar, wanita petani, kabupaten jember

Abstract

Sweet potato is a foodstuff containing carbohydrate which has advantages compared to other carbohydrate sources. One of the sub-districts in Jember Regency which mostly cultivates sweet potato plants is Panti District, Pakis Village, Kemundungan Hamlet. All the time the farmer group sells sweet potatoes in the form

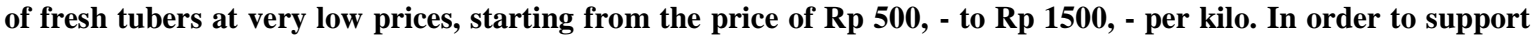
agricultural development towards the realization of sustainable superior agriculture based on local resources, our dedication team will carry out the program "Development of Various Flavored Sweet Potato Chips Products and Its Marketing Strategies for the Welfare of Rengganis's Women Farmers Group in Jember" to increase food independence, added value, competitiveness and welfare of farmers. Methods: The types of training that will be given involves providing training in making chips with the Deep Frying method, as well as providing marketing strategy training in order the products can develop and sell well in the market. The executor of the activity consists of one chief executive who is competent in entrepreneurship, and one executive member who is competent in mechanization of food processing equipment. Results: Outputs to be achieved are an increase in competitiveness and application science and technology for the community of farmers women in Rengganis, Jember. This activity will be carried out for 8 months with a total cost needed, around Rp. 47,500,000. Conclusion: Increased knowledge and competitiveness of farmers women in Rengganis, Jember.

Keywords : Sweet potato, women farmers, jember regency 


\section{PENDAHULUAN}

Bahan pangan merupakan salah satu komoditas agroindustri yang mengalami peningkatan dan memiliki permintaan pasar dalam negeri yang cukup tinggi. Dalam pengembangan agroindustri disesuaikan pula dengan potensi wilayah yang ada. Salah satu komoditas bahan pangan yang banyak dikembangkan di Indonesia adalah ubi jalar. Tingkat harga ubi jalar yang rendah dan terjangkau oleh semua lapisan masyarakat, merupakan salah satu faktor penting untuk mendorong diversifikasi pangan pokok selain beras [1]. Selain itu, ubi jalar berpotensi untuk dikembangkan menjadi sumber karbohidrat alternatif [4]. Dilihat dari segi budidayanya, ubi jalar sangat potensial di Jawa Timur mengingat produksinya pada tiga tahun terakhir mencapai 1.056.136 ton [2].

Ubi jalar merupakan bahan pangan sumber karbohidrat yang memiliki kelebihan dibanding sumber karbohidrat yang lain seperti beras, gandum dan ubi kayu, yaitu karena kandungan vitamin dan komponen antioksidannya yang cukup tinggi, serta serat yang dapat dimanfaatkan sebagai prebiotik [3]. Komoditas ubi jalar diusahakan di sebagian kecamatan di Kabupaten Jember. Jumlah luas lahan, produksi dan produktivitas yang fluktuatif ini berpengaruh terhadap konsumsi ubi jalar oleh masyarakat di Kabupaten Jember.

Salah satu kecamatan yang banyak membudidayakan tanaman ubi jalar yaitu Kecamatan Panti, tepatnya di Desa Pakis, Dusun Kemundungan. Pada Desa Kemundungan tersebut, terdapat kelompok tani yang bernama "Wanita Tani Rengganis". Kelompok tani tersebut membudidayakan tanaman ubi jalar dengan luas areal sebesar 49 Ha. Per hektarnya kelompok tani tersebut dapat menghasilkan ubi jalar kurang lebih 10 ton, yang artinya kelompok tani tersebut dapat menghasilkan kurang lebih 490 ton ubi jalar pertahunnya. Selama ini kelompok tani tersebut menjual ubi jalar dalam bentuk umbi segarnya saja dengan harga yang sangat rendah, mulai dari harga Rp 500,- hingga Rp 1500,- perkilonya. Ubi jalar tersebut biasanya akan dikirim ke Lawang (Bak Pao Telo), Jember, dan Lumajang.

Permasalahan yang terjadi yaitu melimpahnya hasil pertanian ubi jalar yang tidak diimbangi dengan penguasaan ilmu dan teknologi dalam pengolahan ubi jalar, sehingga Kelompok Wanita Tani Rengganis hanya mengetahui bagaimana memproduksi pohon ubi jalar, tetapi tidak mengetahui bagaimana pengolahan ubi jalar menjadi produk lainnya. Hal ini mengakibatkan rendahnya harga dari ubi jalar.

Dalam rangka mendukung pembangunan pertanian menuju terwujudnya pertanian unggulan berkelanjutan yang berbasis sumberdaya lokal, tim pengabdian kami akan melaksanakan program "Pengembangan Produk Kripik Tela Aneka Rasa Dan Strategi Pemasarannya Untuk Kesejahteraan Kelompok Wanita Tani Rengganis Jember" yang bertujuan untuk meningkatkan kemandirian pangan, nilai tambah, daya saing dan kesejahteraan petani.

\section{TARGET DAN LUARAN}

A. Target Program

Target yang ingin dicapai dalam program pengabdian ini adalah:

1. Pengetahuan

Dengan adanya program pengabdian ini dapat memberikan pemahaman tentang pengolahan ubi jalar dan strategi pemasarannya untuk kesejahteraan Kelompok Wanita Tani Rengganis Jember

2. Ketrampilan

Tujuan utama dari kegiatan pengabdian kepada masyarakat ini, tentunya adalah membawa suatu pembaharuan terutama bagi anggota Kelompok Wanita Tani Rengganis Jember. Pembaharuan yang dimaksud yaitu adanya peningkatan ketrampilan, utamanya dalam hal diversifikasi olahan ibu jalar. Selain itu, dengan adanya usaha produksi ini, membuka peluang usaha serta sumber pendapatan baru bagi ibu - ibu anggota Kelompok Wanita Tani Rengganis Jember. Ibu - ibu anggota Kelompok Wanita Tani Rengganis Jember juga menjadi lebih bersemangat, karena memiliki kegiatan positif baru, dimana kegiatan usaha ini tetap berjalan tanpa harus meninggalkan kewajiban sebagai ibu rumah tangga.

B. Luaran Program

Luaran yang diharapkan akan dihasilkan oleh kegiatan pengabdian masyarakat ini adalah:

1. Peningkatan keberdayaan mitra sesuai permasalahan yang dihadapi

2. Luaran wajib yang dihasilkan dari program pengabdian masyarakat ini adalah jurnal pengabdian J - Dinamika Politeknik Negeri Jember, prosiding ICoFA, serta dimuat pada media massa Radar Jember dan video kegiatan yang diunggah di youtube

\section{METODE PELAKSANAAN}

A. Tahapan Pelaksanaan Program

Tahapan dalam pelaksanaan program pengabdian masyarakat ini adalah sebagai berikut: 
1. Persiapan

Sebelum dilakukan program pengabdian masyarakat terlebih dahulu harus dilakukan survey terhadap lokasi, identifikasi permasalahan, dan kebutuhan dari mitra.

2. Penyelesaian Masalah dan Penyusunan Solusi

Tim pelaksana melakukan penyusunan solusi yang akan ditawarkan untuk menyelesaikan permasalahan mitra

3. Penyampaian Solusi kepada Mitra Tim pelaksana melakukan pemberian bantuan mesin dan alat yang lebih modern, kemudian mengajarkan dan melatih proses pengolahan ubi jalar dengan metode deep frying dan cara pengemasan yang menarik konsumen, selain itu pelatihan mengenai strategi pemasarannya

4. Pendampingan

Pendampingan dilakukan secara rutin pada proses produksi kripik tela aneka rasa dan pemasarannya

5. Evaluasi

Evaluasi tingkat keberhasilan program ini dilakukan melalui pengamatan langsung terhadap produktivitas dan kapasitas usaha kripik tela aneka rasa

B. Metode Pendekatan yang Ditawarkan

1. Studi pustaka

Untuk menyampaikan program pengembangan pengolahan kripik tela aneka rasa dan strategi pemasarannya, maka studi pustaka yang dibutuhkan adalah:

a. Pengetahuan mengenai cara pengolahan produk kripik tela aneka rasa

b. Pengetahuan mengenai strategi pemasaran produk kripik tela aneka rasa

2. Observasi lapang

Kegiatan observasi lapang yang dilakukan adalah pemantauan dan evaluasi untuk perkembangan pengetahuan seta implementasi dari Pengembangan Produk Kripik Tela Aneka Rasa dan Strategi Pemasarannya Untuk Kesejahteraan Kelompok Wanita Tani Rengganis Jember

\section{KELAYAKAN PERGURUAN TINGGI}

Politeknik Negeri Jember sebagai lembaga pendidikan tinggi yang dituntut untuk melakukan Tridarma Perguruan Tinggi, salah satunya adalah pengabdian masyarakat. Politeknik Negeri Jember mewadahi kegiatan staf dosennya dalam kegiatan pengabdian kepada masyarakat dengan memiliki Pusat Penelitian dan Pengabdian Kepada Masyarakat (P3M). kinerja P3M dalam program pengabdian kepada masyarakat, pada tahun 2019 ini melaksanakan Program Penelitian dan Pengabdian Masyarakat dengan sumber dana DRPM (Dana Riset dan Pengabdian Masyarakat)

\section{HASIL DAN LUARAN YANG DICAPAI}

A. Hasil

Kegiatan yang telah dilakukan pada program pengabdian masyarakat ini adalah sebagai berikut:

1. Pendampingan Pelatihan Pengoperasian Alat Dalam Pembuatan Keripik Tela Aneka Rasa

Kegiatan ini dilaksanakan tanggal 18 Juni 2019 pukul $08.00-15.00$ WIB di sekretariat Kelompok Wanita Tani Rengganis. Kegiatan pendampingan alat ini diawali dengan kegiatan penyerahan peralatan penunjang produksi keripik tela aneka rasa. Pada pelatihan pengoperasian alat, mitra dibimbing oleh pelaksana kegiatan Pengabdian kepada Masyarakat mengenai penggunaan peralatan, mulai dari alat pengiris tela, alat penggoreng dengan sistem deep frying, alat spinner peniris minyak, serta sealer kemasan.

2. Pelatihan Pembuatan Keripik Dengan Metode Deep Frying Dan Pelatihan Cara Pengemasan Produk

Kegiatan ini dipandu oleh Ibu Aulia Brilliantina, S.TP, M.P dan Ibu Dian Nurhayati, S.TP yang memiliki kepakaran dalam bidang pengolahan makanan. Kegiatan ini juga diperkuat dengan dukungan dari keterlibatan 3 orang mahasiswa dalam pelaksanaan pengabdian masyarakat.

Pelatihan ini dimulai dengan pemberian materi mengenai tata cara pembuatan keripik tela yang renyah. Dimana, agar diperoleh hasil akhir yang baik. Kemudahan praktek membuat keripik tela semakin dirasakan ketika proses merajang tela dipermudah dengan adanya bantuan alat perajang tela secara manual. Proses pembuatan keripik tela semakin terasa cepat lagi, karena juga difasilitasi alat spinner, yang berfungsi untuk mempercepat proses penirisan setelah penggorengan keripik tela.

Kegiatan ini kemudian dilanjutkan dengan pelatihan tata cara pengemasan yang sesuai dengan produk yang dihasilkan. Produk akhir dari kegiatan ini adalah makanan olahan berupa keripik. Keripik yang dihasilkan juga keripik yang memiliki berbagai macam rasa. Sehingga, kemasan yang sesuai adalah kemasan transparan, dimana konsumen

dapat secara langsung melihat produk. Dalam kegiatan pengabdian ini, kemasan yang digunakan berupa plastik PP Standing Pouch Klip. Agar terlihat lebih menarik kemasan plastik ini dilengkapi dengan label yang menunjukkan informasi produk berupa merk produk, 
komposisi produk, berat produk,tanggal produksi dan kadaluarsa dari produk, jenis rasa dari produk, serta kode izin produksi (P - IRT).

3. Pelatihan Strategi Pemasaran

Kegiatan Pelatihan Strategi Pemasaran ini, dilaksanakan pada tanggal 5 Agustus 2019. Kegiatan ini diikuti oleh seluruh anggota KWT Rengganis mulai pukul 08.00 - 15.00 WIB oleh Elok Kurnia Novita Sari, S.TP, M.P. Kegiatan pelatihan ini diawali dengan pemberian materi mengenai strategi pemasaran. Dimana strategi pemasaran yang coba diperkenalkan adalah sistem pemasaran dengan memanfaatkan media online seperti whatsapp, facebook atau instagram. Pemasaran yang dilakukan tidak hanya bergantung pada media online, namun juga dilakukan pemsaran secara langsung pada warung-warung atau café kopi.

\section{B. Luaran yang Dicapai}

Luaran dan target capaian dalam Program Pengabdian Kepada Masyarakat ini yaitu adanya publikasi ilmiah, artikel media massa lokal, peningkatan pengetahuan masyarakat, dan peningkatan ketrampilan masyarakat, serta adanya dokumentasi kegiatan. Adapun luaran dan target capaian dalam Program Pengabdian Kepada Masyarakat dapat di lihat pada Tabel 1.

Tabel 1. Rencana target capaian luaran

\begin{tabular}{|c|c|c|c|}
\hline No & Jenis Luaran & Proses & $\begin{array}{l}\text { Indikator } \\
\text { Capaian }\end{array}$ \\
\hline \multicolumn{4}{|c|}{ Luaran Wajib } \\
\hline 1 & $\begin{array}{l}\text { Publikasi ilmiah pada } \\
\text { jurnal } \\
\text { ISSN/Prosiding jurnal } \\
\text { Nasional }\end{array}$ & accepted & $\begin{array}{l}\text { Proses } \\
\text { pendaftaran } \\
\text { ICoFA dan J- } \\
\text { Dinamika }\end{array}$ \\
\hline 2 & $\begin{array}{l}\text { Publikasi pada media } \\
\text { masa } \\
\text { cetak/online/repocitory } \\
\text { PT }\end{array}$ & Terbit & $\begin{array}{l}\text { Terbit di Radar } \\
\text { Jember tanggal } \\
7 \text { Agustus } 2019\end{array}$ \\
\hline 3 & Dokumentasi & $\begin{array}{l}\text { Sudah } \\
\text { diunggah }\end{array}$ & Sudah diunggah \\
\hline 4 & $\begin{array}{l}\text { Peningkatan } \\
\text { pengetahuan }\end{array}$ & $\begin{array}{l}\text { Sudah } \\
\text { tercapai }\end{array}$ & $\begin{array}{l}\text { Sudah tercapai, } \\
\text { diketahui } \\
\text { dengan hasil } \\
\text { kuisioner }\end{array}$ \\
\hline \multicolumn{4}{|c|}{ Luaran Tambahan } \\
\hline 5 & $\begin{array}{l}\text { Ketrampilan } \\
\text { meningkat }\end{array}$ & $\begin{array}{l}\text { Sudah } \\
\text { tercapai }\end{array}$ & $\begin{array}{l}\text { Sudah tercapai, } \\
\text { diketahui } \\
\text { dengan produk } \\
\text { kripik telo yang } \\
\text { dihasilkan } \\
\text { terjual (Foto } \\
\text { Kegiatan dan } \\
\text { produk yang } \\
\text { dihasilkan) }\end{array}$ \\
\hline
\end{tabular}

\section{KESIMPULAN DAN SARAN}

\section{A. Kesimpulan}

Kegiatan Pengabdian kepada Masyarakat pengolahan keripik ubi telah dapat dijalankan dengan baik dan tanpa halangan yang berarti.
Seluruh rangkaian peralatan pengolahan keripik tela aneka rasa, telah diterima dengan baik oleh Kelompok Wanita Tani Rengganis Jember. Seluruh anggota Kelompok Wanita Tani Rengganis Jember telah mengikuti rangkaian kegiatan pelatihan pembuatan keripik tela aneka rasa dengan penuh semangat. Adapun hasil kegiatan ini yaitu, adanya peningkatan pengetahuan serta kemampuan dari anggota Kelompok Wanita Tani Rengganis Jember dalam hal produksi keripik tela aneka rasa mulai dari penanganan awal hingga pengemasan. Anggota Kelompok Wanita Tani Rengganis Jember juga mampu mengoperasikan seluruh rangkaian alat produksi dengan baik.

B. Saran

Untuk lebih memaksimalkan peningkatan kesejahteraan para kelompok wanita tani rengganis perlu lebih ditingkatkan program pengabdian kepada masyarakat dengan topik perbaikan desain higiene pada proses pengolahan kripik tela.

Berikut beberapa dokumentasi yang kami lakukan pada kegiatan pengabdian ini

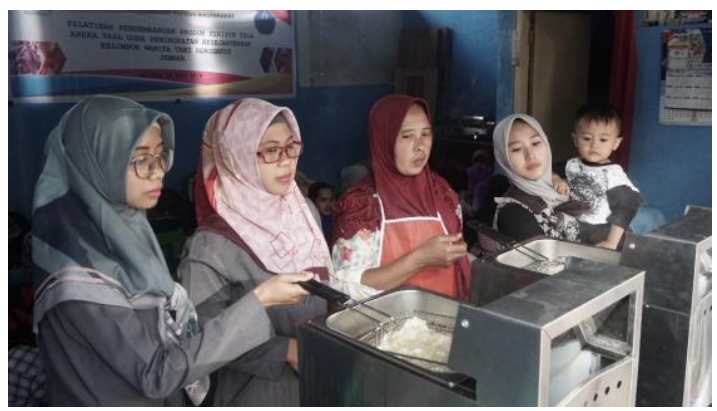

Gambar 1. Pendampingan Penggunaan Alat Pengolahan

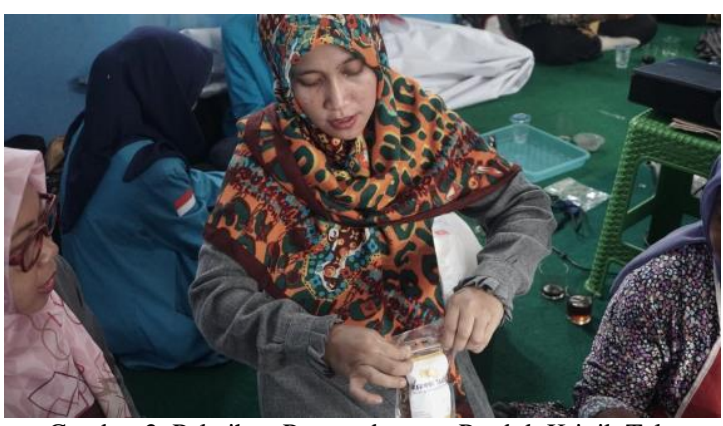

Gambar 2. Pelatihan Pengembangan Produk Kripik Telo 


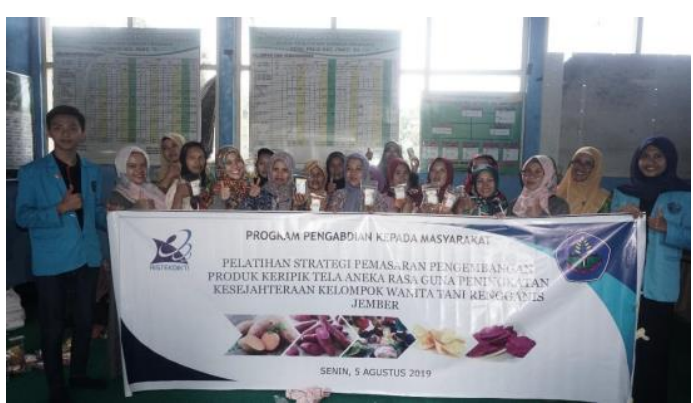

Gambar 3. Kegiatan Pelatihan Strategi Pemasaran

\section{UCAPAN TERIMA KASIH}

Terimakasih penulis ucapkan kepada Kementrian Riset, Teknologi dan Pendidikan Tinggi yang sudah mendanai program pengabdian ini melalui sumber dana DRPM tahun anggaran 2019, dan tidak lupa juga penulis ucapkan kepada Lembaga Penelitian Pengabdian Masyarakat (P3M) Politeknik Negeri Jember yang telah membantu proses penulisan pengabdian kepada masyarakat ini.

\section{DAFTAR PUSTAKA}

[1] Aliyani, Alin. 2013. Potensi Pengembangan Produksi Ubi Jalar (Ipomea Batatas L.)di Kecamtan Cilimus Kabupaten Kuningan. Bandung : Skripsi FPIPS UPI. Tidak diterbitkan

[2] Badan Pusat Statistik. 2015. Produksi Tanaman Ubi Jalar, Jember : Badan Pusat Statistik.

[3] Hariyadi. 2008. Kimia dan Teknologi Pati. PPS UGM Press : Yogyakarta.

[4] Hidayat. 2009. Karakterisasi Tepung Ubi Kayu Modifikasi yang Diproses Menggunakan Metode Pragelatinisasi Parsial. Prodi Teknologi Pertanian. Bandar Lampung. Politeknik Negeri Lampung. 